\title{
Optimization of multi-source complex district heating network, a case study
}

\author{
Mattias Vesterlund ${ }^{a}$, Andrea Toffolo ${ }^{a}$ and Jan Dahl ${ }^{a}$ \\ ${ }^{a}$ Department of Engineering Science and Mathematics, Division of Energy Science, Energy Engineering, \\ Luleå,Sweden, mattias.vesterlund@ltu.se; andrea.toffolo@ltu.se; jan.dahl@ltu.se
}

\begin{abstract}
:
The level of complexity for a district heating network increases with the maturity of the network, and this affects the pattern of the distribution of the hot water from the heat production sites to the end users. The majority of district heating systems are also multi-source networks, typically supported with heat from one main production site and other smaller satellite sites that are activated when required. In general, local energy companies have a lack of knowledge regarding how a meshed network behaves when different production sites are operated. The schedule of heat generation at the different sites is often based on staff experience and some general rules of thumb.

In this paper a method for modeling and simulating complex district networks is further developed in order to optimize the total operating costs of a multi-source network, with constraints on the pressure and temperature levels in the user areas and on the heat generation characteristics at each production site.

The optimization results show that the usage of the cheapest resources is preferred to a distributed generation of heat, even if some of the pipes may exceed the recommended thermal load capacity. The main site water supply temperature is found to be the lowest allowed by the constraint on the temperature of the water supplied to the end users, since the decrease of the costs associated with the lower thermal losses in the network is not counterbalanced by the increase of those associated with the pumping power of a larger water mass flow rate.
\end{abstract}

\section{Keywords:}

Optimization, Multi Source, Complex Network, District Heating.

\section{Introduction}

The evolution of district heating systems has been going on for more than 100 years, and in the beginning the first generation of district heating networks used to transport steam as heat carrier. Today district heating systems are at the end of the third generation, which is characterized by a water supply temperature around $100^{\circ} \mathrm{C}$, material-efficient components, pre-insulated pipes with extruded foam and plastic jacket. District heating is definitely a well developed technology that is used in most larger cities in central and northern Europe.

Each district heating system has its own piping network in order to transport heat from the production sites to the end consumers. Figure 1 shows that often the piping network is started as a set of small separate heating islands that successively grow together into one larger network with an increasing degree of complexity, the extent of the complexity being directly correlated with the maturity of the network. The advantage of using a meshed network (the last stage of network maturity) is that the thermal load for the single pipes is reduced and alternative paths can be used in case of pipe failure. However, the disadvantages are an increase in the thermal losses due to the larger heat dissipation area and the difficulty to determine the pattern of the water mass flow rate within the network [1-3].

More than often, heat generation in a district heating system is planned according to the experience of the staff running the production facilities and some general rules of thumb. There is a general lack of knowledge in determining the optimal heat production plan for a system involving multiple sources (usually one main production plant supported by satellite, or just back-up, boiler plants) and a meshed piping network. The challenge is to be able to evaluate how the total heat production cost 
is affected by the heat output, the supply temperature, the thermal efficiency of each heat production site combined with the thermal and pressure losses in the piping network for a given scenario characterized by the demand from the end users and the environmental conditions.
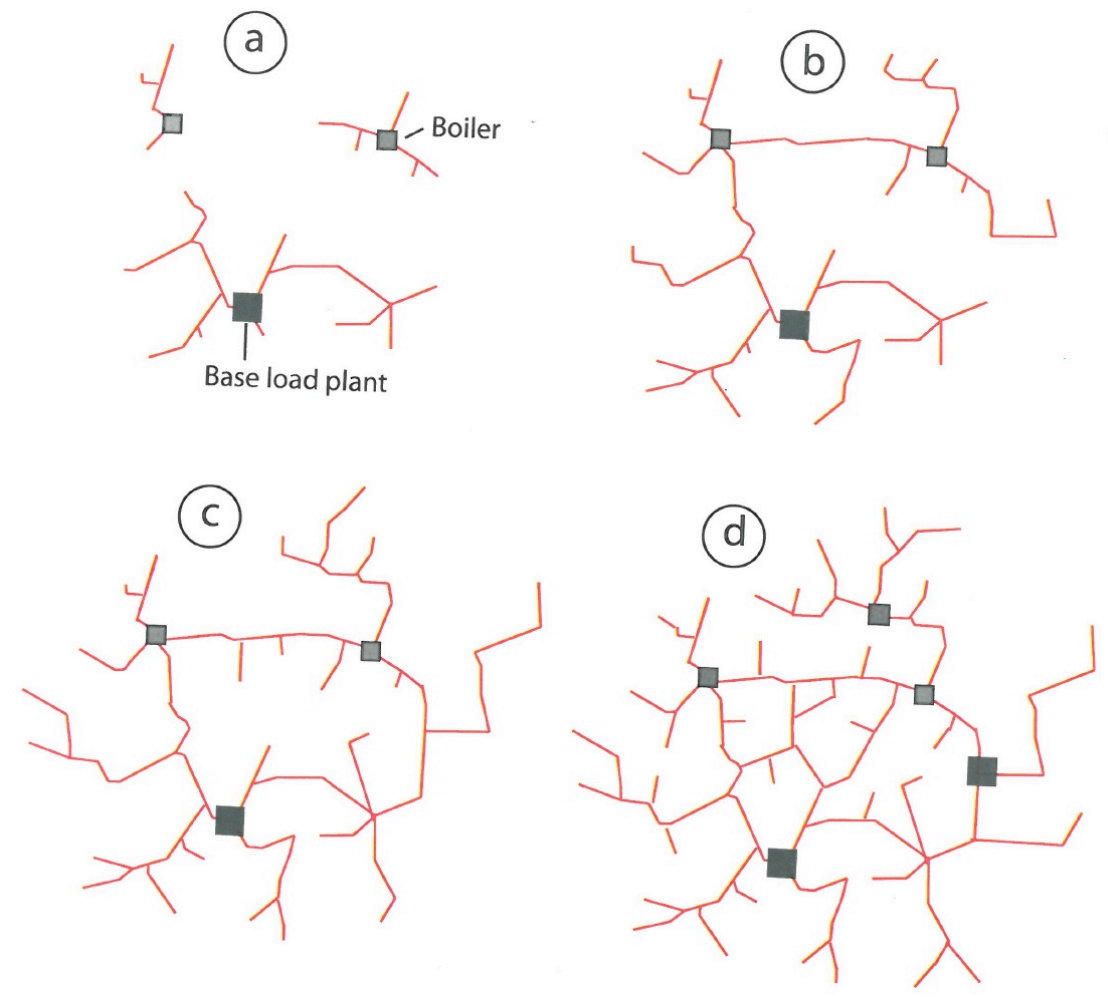

Fig. 1. Evolution of network designs, a) network with island, b) coherent network with tree structure, c) network with ring, d) meshed network [2].

A literature review in the field of heat production for meshed district heating proves that current knowledge is still insufficient, For instance, Bordin et al. [4] highlight a general need for the further development of district heating models including meshed networks and multi-source heat production and present preliminary results showing the potential to solve realistic sized networks. Fazlollahi [5] demonstrates that the annual operating cost can be reduced by almost $30 \%$ and a higher thermal efficiency can be obtained with an optimization procedure that selects the resources, decentralized vs. centralized heat production technologies and the configuration of the piping network. Wang et al. [6] find that the optimal location for a peak load boiler is a peripheral position within the network (i.e. far away from the main plant) close to an area that is dense of end users. On the other hand, the peak load boiler should be placed within the main plant if the electricity from combined heat and power generation can be used on site. Fang and Risto [7] performed the optimization for a multi-source system with two heat production sites, the district heating network being simply represented as a sink. In their model boiler efficiency and the cost for heat production is not affected by the supply or return water temperature. It is concluded that in sparse networks thermal losses represent the dominating term in the total cost, which results in a lower supply temperature from the heat production sites and higher water mass flow rates in the pipes. Olsson et al. [8] believe that an investigation of the environmental benefits of district heating would increase the exploitation of European heat generation potential into district heating systems.

The present group of authors has already developed a methodology for the simulation and the analysis of the behaviour of a multi-source complex district heating network $[9,10]$. The novelty introduced in this paper is the optimization of the operation of such kind of network by minimizing the total cost related to the heat generation at the production sites and to its delivery to the end users. As in the previous works, the district heating network of Kiruna, a small town located in 
northern Sweden, is used a case study to illustrate the methodology. In the following sections of the paper the specific case study is introduced, the methodology about the simulation model of complex meshed network is described, the optimization problem and the algorithm used to solve it are presented, the results from the optimization runs are discussed and finally some conclusion are drawn.

\section{Case study}

The town of Kiruna is located in the very north of Sweden, $150 \mathrm{~km}$ above the Artic Circle, and it is well within the sub-artic climate zone, with an annual average temperature between -1.5 to $-3^{\circ} \mathrm{C}$. This results in a substantial need for room heating in the buildings where the 18,000 inhabitants of Kiruna spend their lives.

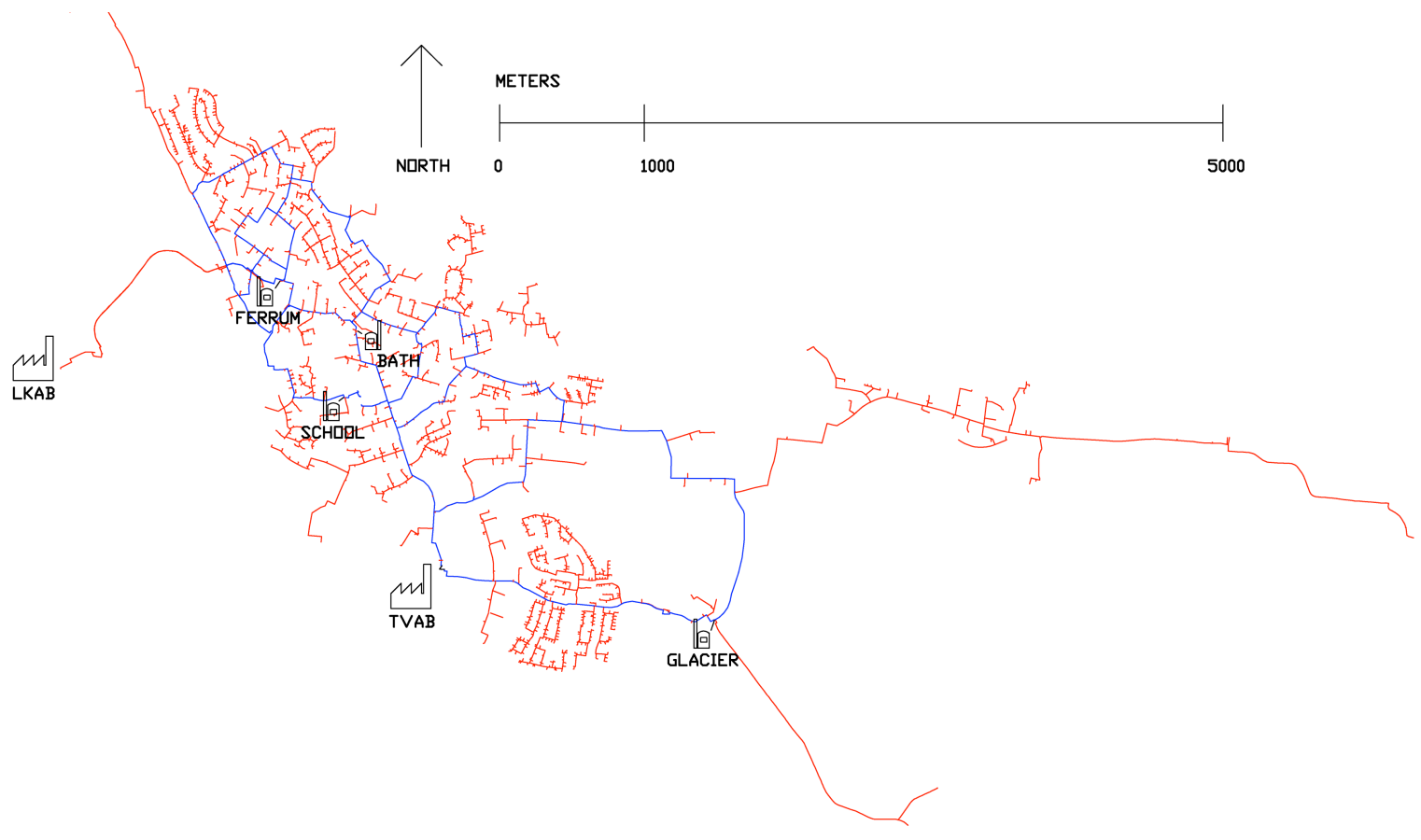

Fig. 2. A scheme of the district heating network in the town of Kiruna: piping loops are shown in blue and consumer feeding branches in red [10].

The district heating network in Kiruna has its origin in the 1960s, when large real estate boilers were connected to other surrounding buildings. In 1980 all heat production was centralized and entrusted to the local energy company Tekniska Verken i Kiruna AB (TVAB). By the middle of the 1980s more than the half of the multifamily and administrative buildings were already connected to the district heating network. By the end of 1990s the network had grown approximately to its current size, supplying heat to $30 \%$ of the small houses as well and $95 \%$ of the premises. Today the network delivers $250 \mathrm{GWh}$ per year of heat through $120 \mathrm{~km}$ of pipes to the about 1700 end users that are connected. Figure 2 shows the current network, which apparently is a mature meshed network with a complex structure (the piping forming the meshed part of the network is marked in blue in the figure while the feeding branches are marked in red).

Heat can be supplied to the network from six different sites, which are also shown in Fig. 1: TVAB (the main heat production site, with waste, biomass and oil boilers), Glacier (oil and electricity boilers), School (oil boilers), Bath (electricity boiler), Ferrum (oil boilers) and LKAB (waste heat from iron ore mining). Table 1 summarizes the type, the minimum/maximum capacities and the efficiencies of the boilers in the six sites. The network data recorded in the year 2010 show that during the coldest day of the year a peak demand of about $49 \mathrm{MW}$ occurred, the temperature of the water supplied to the end users being in the range between 90 and $99^{\circ} \mathrm{C}$. 
Table 1. The main features of the six heat production sites of the district heating network in Kiruna.

\begin{tabular}{|c|c|c|c|c|}
\hline \multirow[t]{2}{*}{ Site/resource } & \multicolumn{2}{|c|}{ Power [MW] } & \multicolumn{2}{|c|}{ Efficiency [\%] } \\
\hline & Min & $\operatorname{Max}$ & Min & Max \\
\hline \multicolumn{5}{|l|}{ TVAB } \\
\hline Bio-boiler & 2 & 6 & 77 & 80 \\
\hline Bio-boiler & 2 & 6 & 71 & 83 \\
\hline Oil bolier & 4 & 10 & 82 & 94 \\
\hline Waste boiler & 5.1 & 27 & 85 & 101 \\
\hline \multicolumn{5}{|l|}{ Glacier } \\
\hline Oil boiler & 0.6 & 1.2 & 82 & 84 \\
\hline Oil boiler & 1.2 & 2.3 & 83 & 85 \\
\hline Oil boiler & 1.2 & 2.3 & 84 & 86 \\
\hline Electric boiler & 0.4 & 1.2 & 89 & 91 \\
\hline \multicolumn{5}{|l|}{ Bath } \\
\hline Electric boiler & 3 & 10 & 89 & 91 \\
\hline \multicolumn{5}{|l|}{ Ferrum } \\
\hline Oil boiler & 1.1 & 2.2 & 82 & 84 \\
\hline Oil boiler & 1.1 & 2.2 & 83 & 85 \\
\hline Oil boiler & 1.5 & 3 & 84 & 86 \\
\hline \multicolumn{5}{|l|}{ School } \\
\hline Oil boiler & 1 & 2 & 80 & 82 \\
\hline Oil boiler & 1 & 2 & 81 & 83 \\
\hline Oil boiler & 1 & 2 & 82 & 84 \\
\hline Oil boiler & 1.8 & 3.5 & 83 & 85 \\
\hline Oil boiler & 1.8 & 3.5 & 84 & 86 \\
\hline \multicolumn{5}{|l|}{ LKAB } \\
\hline Waste heat & 1 & 15 & 92 & 98 \\
\hline
\end{tabular}

\section{Methodology}

The methodology used in this paper is based on the procedure for modelling complex meshed district heating networks that has already been developed and applied to the Kiruna case in $[9,10]$. A hybrid evolutionary-MILP optimization algorithm is then coupled to the model of the district heating network in Kiruna to minimize the total operating cost due to the heat generation at the production sites and its delivery to the end users.

\subsection{The model of the DHS}

The model for the simulation of meshed district heating networks $[9,10]$ has been developed in the MATLAB/Simulink environment. The main idea behind the model is to obtain a completely modular simulation tool, so that complex network configurations can be represented by combining few categories of blocks in a custom diagram. The blocks have to be connected in a specific way in order to ensure a correct exchange of information among them, as it appears from the brief summary of block categories that is offered in the following.

Node blocks: A node block represents a junction in the piping network. In this block mass and enthalpy balances are evaluated both for the supply and the return network according to the incoming and outgoing flows from/to the other blocks (pipes, users, heat production sites type II), in order to determine the local pressure and temperature at the node.

Pipe blocks: A pipe block represents a segment of the piping network, which is made of a supply pipe and a return pipe. From the information about the pressures and temperatures at the nodes connected by the pipe, the mass flow rate in the pipe and the associated enthalpy flows are determined for both the supply and return network. The incoming and outgoing enthalpy flows differ because of the thermal losses in the pipes, which are calculated as a function of the temperature of the water entering the pipes.

User blocks: A user block represents a group of consumers, the demand of which is specified. It has to be connected to a node block, from which the temperature of the supply network is retrieved. The heat demand and the water supply temperature are used to calculate the temperature drop due to the delivery of heat (according to a characteristic surface that is specific for the represented group of consumers), and hence the water mass flow rate that is taken from the supply network and 
discharged to the return network. The enthalpy flow to the return network also takes into account the thermal losses in the branch of the network that feeds the represented group of consumers.

Heat production site blocks: A heat production site (which may comprise several different thermal facilities in the same site, e.g., a group of boilers fed by different fuels) can be represented in two ways. Type I: The block is characterized by the assigned values of supply pressure and temperature of the water at the production site (therefore it has to be connected to a pipe block, and at least one of these blocks has to be included in the model to set a reference for the calculation of pressure along the network). The heat supplied by the site is one of the simulation outputs and can be calculated from the mass flow rate of the water that is taken from the site and the return temperature of the water that is sent back to the site. Type II: The block is characterized by the values assigned to the amount of heat that is supplied into the network and to the temperature at which it is supplied. The block has to be connected to a node block, which provides the temperature of the water taken from the return network in order to calculate the mass flow rate of the water that is heated in the site.

The model for the meshed district heating network in Kiruna is made of 6 heat production site blocks ( 1 type I, TVAB, and 5 type II), 85 pipe blocks, 75 blocks and 44 user blocks.

\subsection{The optimization problem}

The objective of the optimization problem presented in this paper is the minimization of the total operating cost of the district heating system in Kiruna. This cost is made of two terms, the cost for generating the requested heat, which is equal to the overall demand of end users plus the thermal losses along the network, and the cost for making the water circulate in the piping network, which is the sum of the costs for the pumping power required at the heat production sites to introduce the supply water mass flow rates into the network (1). In turn, the cost for the generation of heat is equal to the sum of the costs for the resources (fuels, waste heat or electricity) consumed in the boilers at the production sites, the resource input in energy terms being greater than the heat output according to the efficiency of the boilers. The relationship between the consumed resource and the heat output in each boiler is considered linear and is determined using the boiler efficiencies at maximum and minimum loads reported in Table 1. In this way, the cost for resource consumption at the heat production sites is also linear with the heat generation (see further implications of this in Section 3.3 about the algorithm used to solve the optimization problem). The objective function to be minimized can then be expressed in the following way:

$$
C_{\text {tot }}=\sum_{\text {site res }} \sum_{\text {res }} Q_{\text {res, site }}+\sum_{\text {site }} c_{\text {el }} P_{\text {pump }, \text { site }}
$$

where $c$ are the specific cost of the resources (in Euro/kJ, subscript $e l$ stands for electricity), $Q_{r e s, s i t e}$ is the amount of a resource consumed in a site (expressed in $\mathrm{kW}$ ), $P_{\text {pump,site }}$ is the power (in $\mathrm{kW}$ ) used to drive the pumps of the heat production sites. The order of specific costs for the resources, from the cheapest to the most expensive, is the following: municipal waste (which is negative, TVAB actually gets paid for burning it), biomass, waste heat from LKAB, electricity and oil.

The twelve decision variables of the optimization problem are:

- the water supply temperature at the main heat production site (TVAB);

- the pressure at the eastern outlet of TVAB site (TVAB site has two outlets, the northern one towards the city centre and the eastern one towards the airport. The northern outlet has been considered as the reference for the calculation of pressure along the network);

- the amounts of heat supplied by the other heat production sites (LKAB, Glacier, Ferrum, School and Bath);

- the water supply temperatures at the other production sites.

Some constraints are also considered about the values of pressure and temperature along the district heating network. The maximum pressure difference within the supply network (considering the 
height of the nodes) is not supposed to exceed $12 \mathrm{bars,} \mathrm{while} \mathrm{the} \mathrm{temperature} \mathrm{of} \mathrm{the} \mathrm{water} \mathrm{supplied}$ to a group of consumers is not supposed to go below $65^{\circ} \mathrm{C}$. Penalty terms that are proportional to the violation of these constraints are added to the objective function.

\subsection{The optimization algorithm}

The minimization of the total operating cost for the district heating network in Kiruna is performed by a hybrid evolutionary-MILP optimization algorithm, which has been specifically developed for the solution of this problem. The algorithm is organized hierarchically in two nested levels, the overall search process being driven from the upper level by the evolutionary algorithm that is a modified (single-objective) version of the algorithm proposed in [11].

At the beginning of each iteration of the upper level algorithm a set (population) of candidate solutions is available. The usual genetic operators (crossover and mutation) are then applied to the decision variables of a pool of parent pairs that are randomly extracted from the population in order to generate a new set of candidate solutions (offspring population).

The evaluation of the objective function value associated with a given candidate solution starts with the simulation of the network operating conditions identified by its decision variable values. The simulation returns important information, namely the pressures and the mass flow rates in the network, from which the pumping power at the heat production sites can be determined, and the heat output at the TVAB site. Note that this is the only heat output that is not fixed by the decision variables, so it must be equal to the difference between the overall user demand and the output of the other sites, plus the thermal losses along the network. The information about the heat output of the production sites is then passed to the lower level optimization algorithm, which solves for each site a MILP problem that minimizes the costs for the heat generation in the site by selecting the loads of the available boilers. The results are returned to the upper level algorithm, which has finally all the pieces of information to evaluate the total operating cost for the candidate solution.

At the end of the iteration of the upper level algorithm, the solutions of the current population and those of the offspring population undergo a selection step in order to form the population for the next iteration. The selection criterion is of course based on the ranking of the objective function values, but also on the genetic diversity of the solutions in order to avoid a premature convergence to sub-optimal solutions.

The algorithm was run with a population of 100 solutions, and 300 to 400 generations were usually sufficient to get a clear indication that the search process had converged around the current best solution.

\section{Results}

The optimization of the total operating cost of the district heating network in Kiruna is performed considering six cases, which result from the combination of two levels of end user demand (49MW, the peak demand in the coldest day of winter 2010, and 39MW, which is a quite common demand level during winter time) and three scenarios involving different sets of available heat production sites. In the first scenario ("all plants") all the heat production sites are considered to satisfy the network thermal requirement. However, under particular conditions the LKAB company can refuse to sell to the network the waste heat from the iron mining facilities, in order to use it internally. Since LKAB can cover a large share of the network requirement with a relatively cheap resource, this situation is worth to be represented in a specific scenario ("no LKAB"), in which all the heat production sites but LKAB are considered as potentially active. A third scenario is finally considered, in which the 10MW electric boiler of the Bath site is also inactive ("no LKAB, Bath"). In fact, it is expected that the Bath site will be often used instead of the oil boilers because of the lower price of electricity and the large capacity of the electric boiler, so in this third scenario at least some of the oil boilers should be forced into operation.

Table 2 summarizes the results of the optimization runs, showing the details of the operating conditions of the heat production sites (boiler heat output and temperature of the water supplied to 
the network) that minimize the total operating cost for heat generation and delivery in the six considered cases. Note that the difference between the sum of the amounts of heat generated at the production sites and the end user demand is equal to the thermal losses in the network.

Table 2. The optimal conditions that minimize the total operating cost of the district heating network in Kiruna for all the six considered cases.

\begin{tabular}{|c|c|c|c|c|c|c|c|c|c|c|c|c|c|}
\hline \multirow[b]{2}{*}{ Site/resource } & \multirow[b]{2}{*}{ Max } & \multicolumn{2}{|c|}{$49 \mathrm{MW}$ (all plants) } & \multicolumn{2}{|c|}{$39 \mathrm{MW}$ (all plants) } & \multicolumn{2}{|c|}{$49 \mathrm{MW}$ (no LKAB) } & \multicolumn{2}{|c|}{$39 \mathrm{MW}$ (no LKAB) } & \multicolumn{2}{|c|}{$49 \mathrm{MW}$ (no LKAB, Bath) } & \multicolumn{2}{|c|}{39 MW (no LKAB, Bath) } \\
\hline & & Power & Temperature & Power & Temperature & Power & Temperature & Power & Temperature & Power & Temperature & Power & Temperature \\
\hline & {$[\mathrm{MW}]$} & {$[\mathrm{MW}]$} & {$\left[{ }^{\circ} \mathrm{C}\right]$} & {$[\mathrm{MW}]$} & {$\left[{ }^{\circ} \mathrm{C}\right]$} & {$[\mathrm{MW}]$} & {$\left[{ }^{\circ} \mathrm{C}\right]$} & {$[\mathrm{MW}]$} & {$\left[{ }^{\circ} \mathrm{C}\right]$} & {$[\mathrm{MW}]$} & {$\left[{ }^{\circ} \mathrm{C}\right]$} & {$[\mathrm{MW}]$} & {$\left[{ }^{\circ} \mathrm{C}\right]$} \\
\hline TVAB & & 39.0 & 74.3 & 39.0 & 71.7 & 45.1 & 69.7 & 39.0 & 71.9 & 49.0 & 69.5 & 45.4 & 71.3 \\
\hline Bio-boiler & 6.0 & 6.0 & & 6.0 & & 6.0 & & 6.0 & & 6.0 & & 6.0 & \\
\hline Bio-boiler & 6.0 & 6.0 & & 6.0 & & 6.0 & & 6.0 & & 6.0 & & 6.0 & \\
\hline Oil boiler & 10 & - & & - & & 6.1 & & - & & 10.0 & & 6.4 & \\
\hline Waste boiler & 27.0 & 27.0 & & 27.0 & & 27.0 & & 27.0 & & 27.0 & & 27.0 & \\
\hline Glacier & & - & - & - & - & 1.2 & 77.4 & 0.6 & 92.8 & 2.9 & 75.4 & 12 & 75.0 \\
\hline Oil boiler & 1.2 & - & & - & & - & & - & & 1.7 & & - & \\
\hline Oil boiler & 2.3 & - & & - & & - & & - & & - & & - & \\
\hline Oil boiler & 2.3 & - & & - & & - & & - & & - & & - & \\
\hline Electric boiler & 1.2 & - & & - & & 1.2 & & 0.6 & & 1.2 & & 1.2 & \\
\hline School & & - & - & - & - & - & - & - & - & 4.3 & 75.0 & - & - \\
\hline Oil boiler & 2.0 & - & & - & & - & & - & & 1.0 & & - & \\
\hline Oil boiler & 2.0 & - & & - & & - & & - & & - & & - & \\
\hline Oil boiler & 2.0 & - & & - & & - & & - & & - & & - & \\
\hline Oil boiler & 3.5 & - & & - & & - & & - & & 3.3 & & - & \\
\hline Oil boiler & 3.5 & - & & - & & - & & - & & - & & - & \\
\hline Bath & & 3.1 & 92.7 & - & - & 10.0 & 75.0 & 7.1 & 76.9 & $x$ & $x$ & $x$ & $x$ \\
\hline Electric boiler & 10.0 & 3.1 & & - & & 10.0 & & 7.1 & & $x$ & & $x$ & \\
\hline & & & & & & & & & & & & & \\
\hline Ferrum & & - & - & - & - & - & - & - & - & - & - & - & - \\
\hline Oil boiler & 2.2 & - & & - & & - & & - & & - & & - & \\
\hline Oil boiler & 2.2 & - & & - & & - & & - & & - & & - & \\
\hline Oil boiler & 3.0 & - & & - & & - & & - & & - & & - & \\
\hline & & & & & & - & & & & & & & \\
\hline LKAB & & 15.0 & 77.5 & 8.0 & 75.1 & $x$ & $x$ & $x$ & $x$ & $x$ & $\mathrm{x}$ & $x$ & $x$ \\
\hline Waste heat & 15.0 & 15.0 & & 8.0 & & $x$ & & $x$ & & $x$ & & $x$ & \\
\hline
\end{tabular}

It appears that in all cases the largest share of the network heat requirement is covered by the waste boiler and the biomass boilers at the TVAB site, which are always active and at full load since municipal waste and biomass are the two cheapest resources. When LKAB site is active ("all plants" scenario) the rest of the requirement is covered with waste heat from the iron mining facilities and, in the case of peak end user demand, with Bath electric boiler as well.

When LKAB site is inactive ("no LKAB" scenario) Bath and Glacier electric boilers are used at partial or at full load. If their capacity is not sufficient to satisfy the network requirement, the large TVAB oil boiler comes into play. In case Bath electric boiler is also unavailable ("no LKAB, Bath" scenario) and the end user demand is $49 \mathrm{MW}$ the network requirement quota exceeding the capacities of Glacier electric boiler and TVAB oil boiler is covered by smaller oil boilers at Glacier and School sites.

These results clearly show that the minimization of the total operating cost for the Kiruna district heating network privileges the cost of the resources over a distributed generation of heat. Cheapest resources are always used first in the boilers with the highest efficiency, the efficiency being a function of the load with highest efficiency at maximum boiler capacity. Only when one of the two most expensive resources has to be used in more than one boiler at partial load (e.g. electricity in the "no LKAB"-39MW case or oil in the "no LKAB, Bath"-49MW case), then the share of the load that has to be covered with that resource is split by the optimizer among different heat production sites in different city locations. A better geographical distribution of heat generation in the network would probably be achieved if all the secondary heat production sites had at least one electric boiler of small-to-medium size (from 3 to $5 \mathrm{MW}$ ), and in that case the results may be similar to those obtained in [6].

The optimal temperatures at which the hot water is supplied to the network at the heat production sites is generally quite low, between $70^{\circ} \mathrm{C}$ and $75^{\circ} \mathrm{C}$, which results in high water mass flow rates in the pipes. This indicates that the higher cost for pumping such high mass flow rates is more than 
compensated by the lower requirement for heat generation due to the lower heat losses in the network. This result confirms the findings in [7], and is in contrast with the higher water supply temperatures that are currently used in the real network (see the simulations in $[9,10]$ ).

It is reasonable to affirm that the water supply temperatures should assume the lowest possible value that comply with the constraint on the temperature of the water supplied to the end users (which has to be greater than $65^{\circ} \mathrm{C}$ ). This is however difficult to achieve in just some hundred generations of the hybrid optimization algorithm, since the objective function is much more sensitive to a variation of the amount of heat generated in the sites than to a variation of the water supply temperatures.

\subsection{Network behaviour}

Each scenario considered above can be visualized with data post-processing techniques in order to study several features of the flow patterns in the meshed part of the supply network, such as:

- the directions of the flows and the thermal loads in the pipes,

- non-obvious paths followed by the hot water (paths that are longer than needed are used to transport the water from one bifurcation of the meshed network to an end user along a loop),

- bottlenecks (pipes through which a high mass flow rate is forced, also characterized by excessive thermal loads),

- and sinks (the nodes which have two or more flows as inlets, the only outlet being the user group served by the node).

Figures 3, 4 and 5 show the visualization of flow patterns for three cases with peak end user demand (the other three cases are not shown here for sake of brevity). In the figures, the active heat production sites are shown in red, while the inactive ones are shown in black. The pipes of the meshed network are coloured according to the ratio between the actual pipe thermal load and the capacity recommended by the manufacturer, with a colour scale that ranges from black (0-30\%) to red (above 100\%). The direction of the flow is indicated with black arrows on the pipe segments. The sinks are also shown as blue circles.

There is a significant difference in the features of the flow patterns between the scenario in which LKAB site is active (Fig. 3) and the other two in which it is inactive (Figs. 4 and 5). In the "all plants" scenario with peak end user demand the LKAB site introduces into the northern part of the network a considerable water mass flow rate. This results in a general reduction of the thermal loads in the pipes, in particular along the "backbone" of the network, i.e. the piping transporting the hot water from the northern outlet of the TVAB plant to the northern districts of the town. It is apparent that in Figures 4 and 5 the main pipes along the backbone and some of their ramifications have a load between $70 \%$ and $100 \%$ of the recommended capacity (yellow and orange colours). Overloaded (red) pipes are present in the network at LKAB site outlet (Fig. 3), in a minor loop of the network (Figs. 4 and 5) and at the outlet of the School site (Fig. 5), all being the consequence of undersized diameters in the design procedure.

Another difference caused by the operation of the LKAB site is the inversion of the flow direction in the pipes going east and south from the node at which the LKAB hot water enters the meshed network. This causes the formation of a fourth sink in the network, immediately west of the School site, where the water coming from the LKAB site meets that coming from the TVAB site along the backbone. The hot water coming from the Bath site has also a similar effect on the flow directions in the piping going east from the site, with a fourth sink appearing in Figure 4 where the water coming from the Bath and TVAB sites meet. 


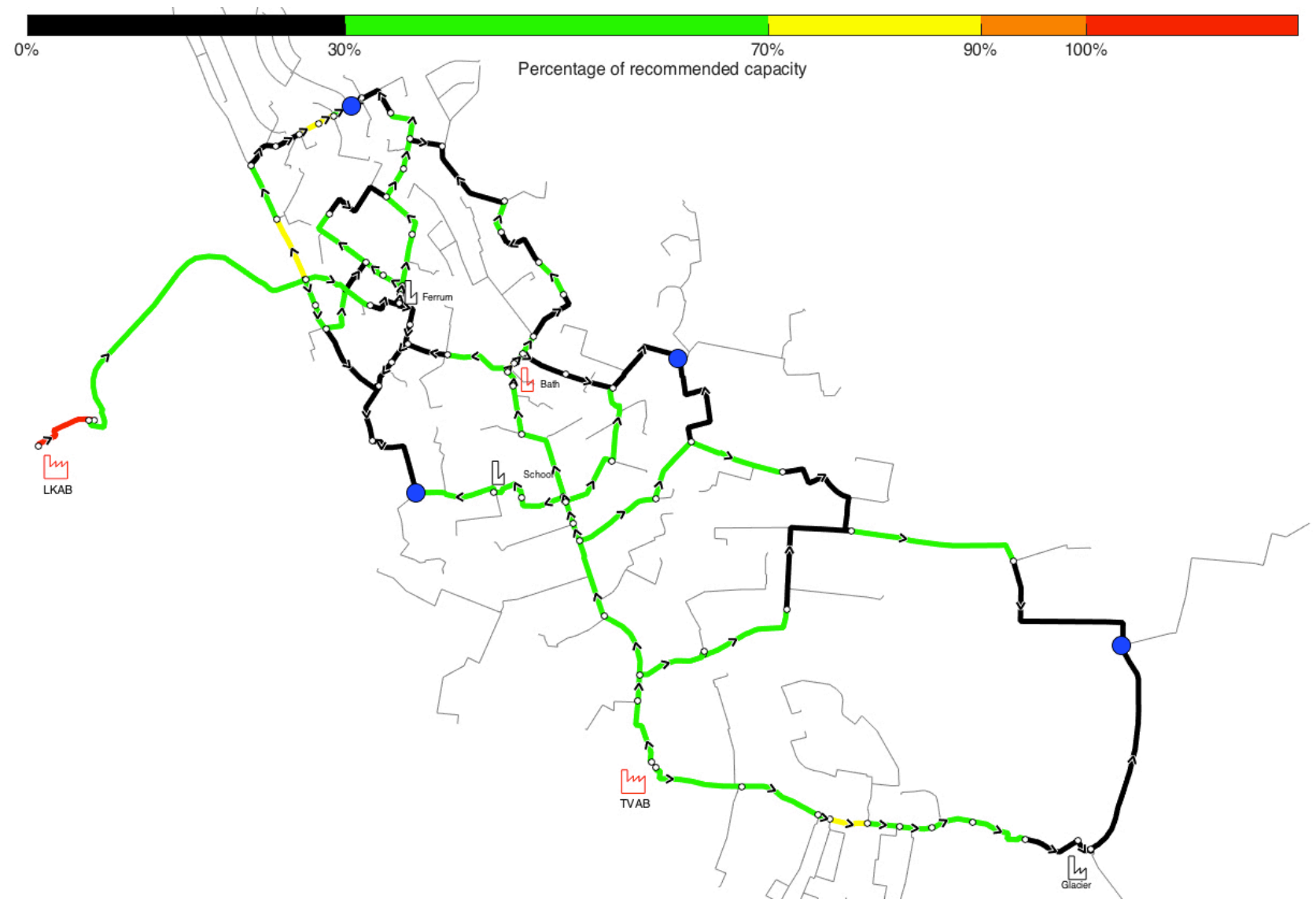

Fig. 3. Flow pattern of case "all plants"-49MW.

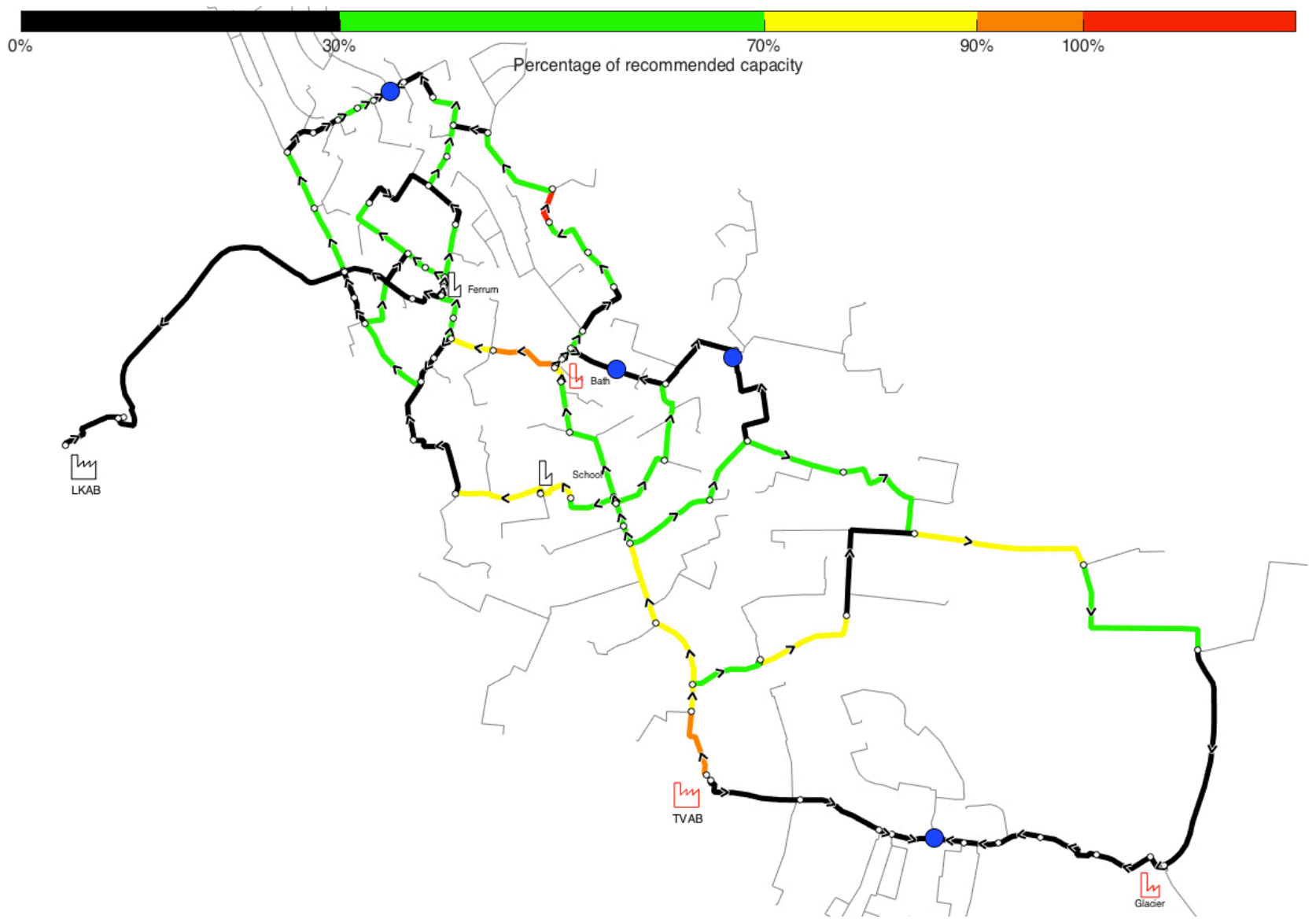

Fig. 4. Flow pattern of case "no LKAB"-49MW. 


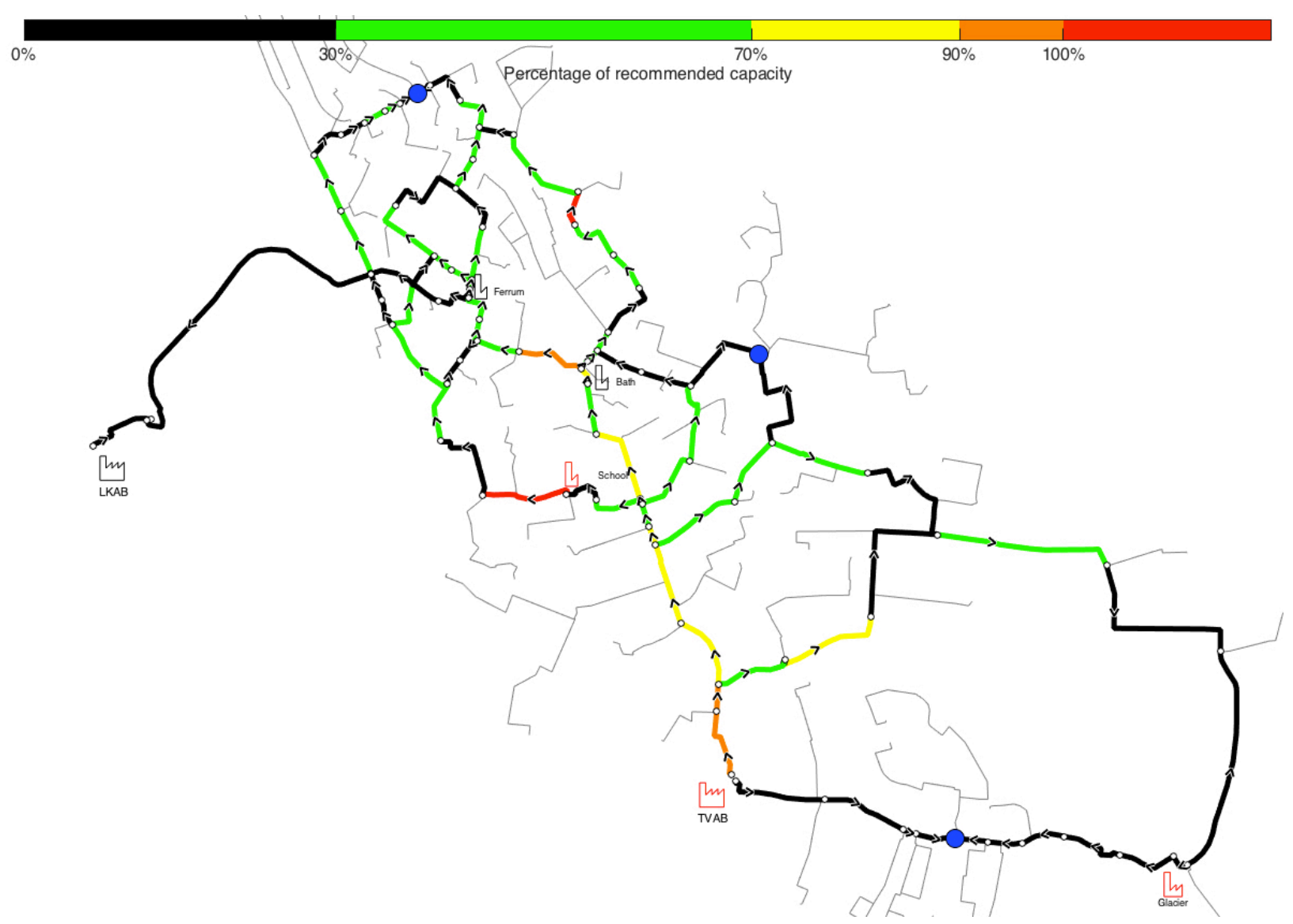

Fig. 5. Flow pattern of case "no LKAB, Bath"-49MW.

It is also worth noting that the sink in the large southern network loop, i.e. the sink where the water mass flow rates coming from the two outlets of the TVAB site meet, changes its position from the easternmost node of the network (Fig. 3) to one of the nodes along the branch between the TVAB and Glacier sites (Figs. 4 and 5). This creates a long non-obvious path from the northern outlet of the TVAB site to the sink, since the distance between the eastern outlet of the TVAB site and the sink is shorter by several hundred meters.

\section{Conclusions}

A case study about the optimization of multi source district heating networks has been presented in this paper for the town of Kiruna. A modular modelling and simulation tool for complex meshed networks is used to investigate the conditions that minimize the total operating cost of not only the generation of heat at the production sites but also of its delivery to the end users. A hybrid evolutionary-MILP algorithm has been developed and coupled to the network simulations in order to solve this specific optimization problem.

The results of the optimization show that due to the specific characteristic of the district heating network in Kiruna a distributed heat generation is not able to reduce the total operating cost. The cheapest resources are consumed in the most efficient boilers irrespective of their location inside the network. The influence of the pumping power on the total operating cost is also minor, the optimal supply temperature at the heat production sites being the lowest compatible with the service to the end users in order to reduce as much as possible the thermal losses along the distribution network. The features of the flow patterns within the meshed part of the network are significantly affected by the hot water produced at the LKAB site using the waste heat from the iron mining facilities. 


\section{Acknowledgments}

This work is mainly founded by HLRC (Hjalmar Lundbohm Research Centre), which is sponsored by local mining company LKAB, by ATTRACT (Attractive, sustainable habitats in cold climates), a research program financed by VINNOVA (Swedish innovation agency), and by ALICE (Attractive Living in Cold Climate), a research program financed by FORMAS.

\section{References}

[1] Frederiksen S., Wener S., Fjärrvärme - Teori, teknik och funktion. : Studentlitteratur, Lund, 1993.

[2] Frederiksen S., Wener S., District Heating and Cooling. : Studentlitteratur, Lund, 2013.

[3] Lauenburg P., Teknik och forskningsöversikt över fjärde generationens fjärrvärmeteknik. 2014.

[4] Bordin C., Gordini A., Vigo D., An optimization approach for district heating strategic network design. Eur J Oper Res 2016.

[5] Fazlollahi S., Becker G., Ashouri A., Maréchal F., Multi-objective, multi-period optimization of district energy systems: IV-A case study. Energy 2015;84:365-81.

[6] Wang H., Lahdelma R., Wang X., Jiao W., Zhu C., Zou P., Analysis of the location for peak heating in CHP based combined district heating systems. Appl Therm Eng 2015.

[7] Fang T., Lahdelma R., Genetic optimization of multi-plant heat production in district heating networks. Appl Energy 2015;159:610-9.

[8] Olsson L., Wetterlund E., Söderström M., Assessing the climate impact of district heating systems with combined heat and power production and industrial excess heat. Resour Conserv Recycling 2015;96:31-9.

[9] Vesterlund M., Dahl J., A method for the simulation and optimization of district heating systems with meshed networks. Energy Conversion and Management 2015;89:555-67.

[10] Vesterlund M., Toffolo A., Dahl J., Simulation and analysis of a meshed district heating network. Proceeding of 28th International Conference on efficiency, Cost, Optimization, Simulation and Enviromental Impact of Energy Systems 2015.

[11] Toffolo A., Benini E., Genetic diversity as an objective in multi-objective evolutionary algorithms. Evol Comput 2003;11:151-67. 